\title{
An Analysis for the Use of Simulation Modeling in Reducing Patient Waiting Time in Emergency Departments (EDs) in Hospitals
}

\author{
Shailesh Narayanrao Khekale, Cummins College of Engineering for Women Nagpur, India \\ Ramesh D. Askhedkar, K. D. K. College of Engineering, Nagpur, India \\ Rajesh H. Parikh, K. D. K. College of Engineering, Nagpur, India
}

\begin{abstract}
The emergency department (ED) plays crucial role in providing 24-hour healthcare services to the ill with speed, accuracy, and sympathy. ED faces the problem of patient waiting time, which leads to patient dissatisfaction and patient crowding. This paper presents a systematic literature review of simulation of ED in healthcare systems from 1970 to 2013. The objectives of this review are to highlight the importance and role of simulation studies to solve the problem of patient waiting time faced by the ED. It also discusses how simulation can be better applied as a tool to solve these problems. The authors found that these simulation studies focus important insights into ED problems, but they also had some limitations that should be addressed.
\end{abstract}

\section{KEYWORDS}

Emergency Department, Length of Patient Stay, Patient Waiting Time, Simulation

\section{INTRODUCTION}

The emergency department (ED) is a core clinical unit of a hospital. Patient satisfaction and the image of the hospital are significantly influenced by the experience of patients attending the emergency department. If the patients with serious ill health are not treated urgently, it can result in damage, permanent deformity and ultimately the death. The patients entering an ED can be saved only if they arrive at the right time, at the right place, receives the right treatment and right resources. The aspect of speed, accuracy and sympathy are important in the emergency department (HSHRC, n.d.). ED faces serious problem of patient waiting time at various stages which ultimately hampers the quality of health care and leads to patient dissatisfaction. To solve this problem of ED, simulation plays important role from last forty years. Simulation modeling helps not only to understand the present system but also to implement corrective measures and their results can be compared without disturbing the system. Simulation modeling has been used in various countries to improve the quality of health care specifically in the ED. These simulation studies are vigorously studied in this paper. 


\section{METHODOLOGY}

Literature review is carried out from 1970 to 2013. It is implemented as per plan shown in the Figure 1. We used a two-phase approach to identify simulation relevant to problem of waiting time in ED. In the first phase, we searched and analyzed the databases of PubMed, Proquest, ACM, IEEE, and simulation Conferences. These databases are the sources of literature in computer science, operations management, health care, and engineering fields. We applied the search phrases like 'simulation in emergency department', etc. Classification of research papers are carried out on the basis of different ED Simulation for problem solving purpose. In the second phase, we examined the references of these 66 research papers. After this phase, we had a total of 52 simulation studies. Most of these studies were conducted after 1990. Analysis of these papers are carried on basis of patient waiting in ED, simulation modeling, objectives, Modeling techniques, data sources, collection methods and study findings. Different research papers which are studied are shown in Figure 2 with reference to five year span and respective number of referenced papers in that span. The number of paper was obtained up to 2 during 1970 to 1980. It was reduced during span of 1981-1985. It was raised to 3 in span of 1986-1990. After 1991, number was increased drastically which was shown in Figure 2.

\section{ANALYSIS OF SIMULATION STUDIES}

Authors analyzed the simulation studies with respect to: (1)Patient waiting in ED (2)Simulation modeling (3) Objectives (4) Modeling techniques(5) Data sources and collection methods (6) Study findings

\subsection{Patient Waiting in ED}

Excessive patient waiting time in ED is the existing problem in worldwide. It reduces and hampers quality of health care and increases adverse effects on patients with serious illness (Diercks et al.,

Figure 1. Plan for literature review of simulation studies

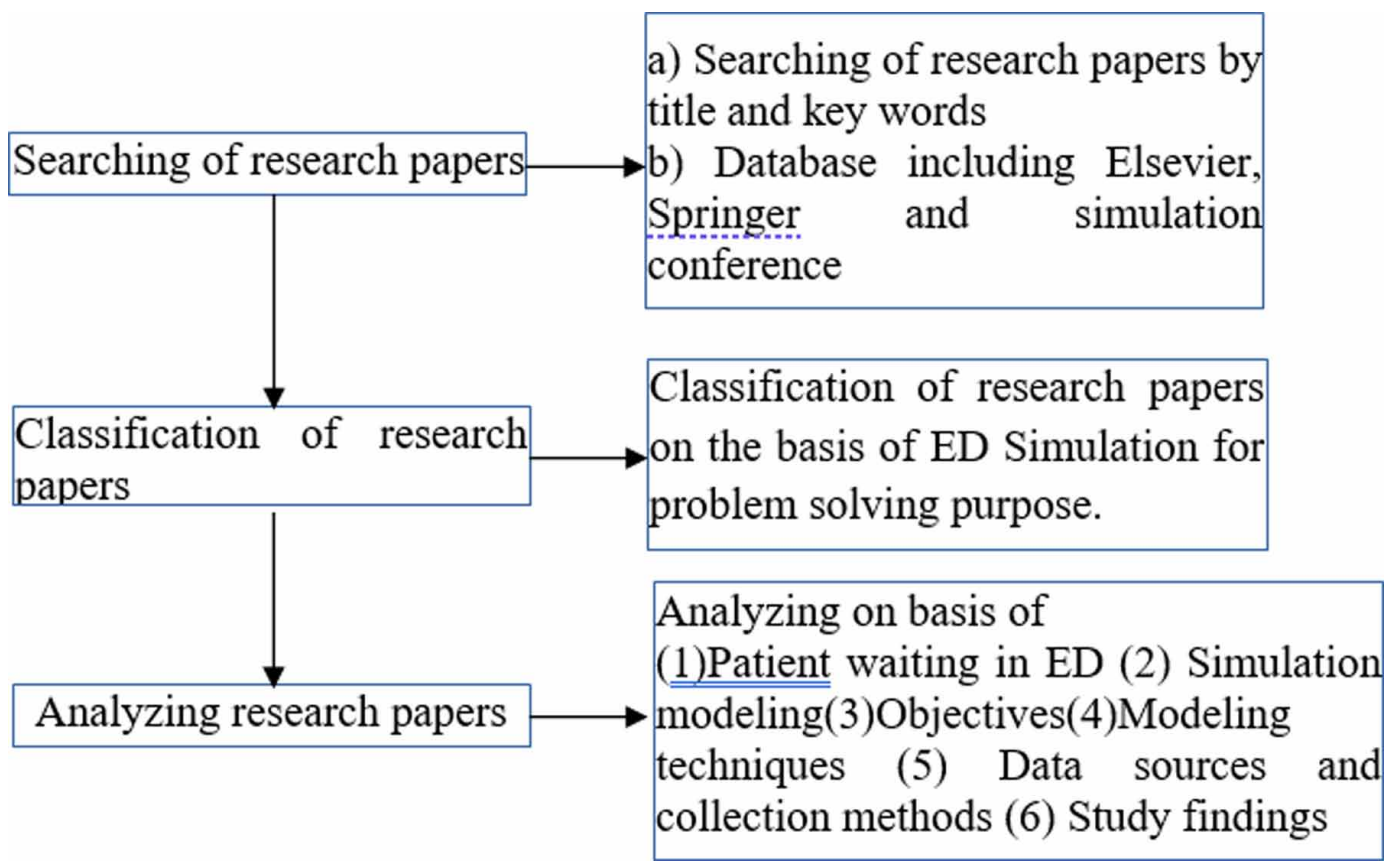




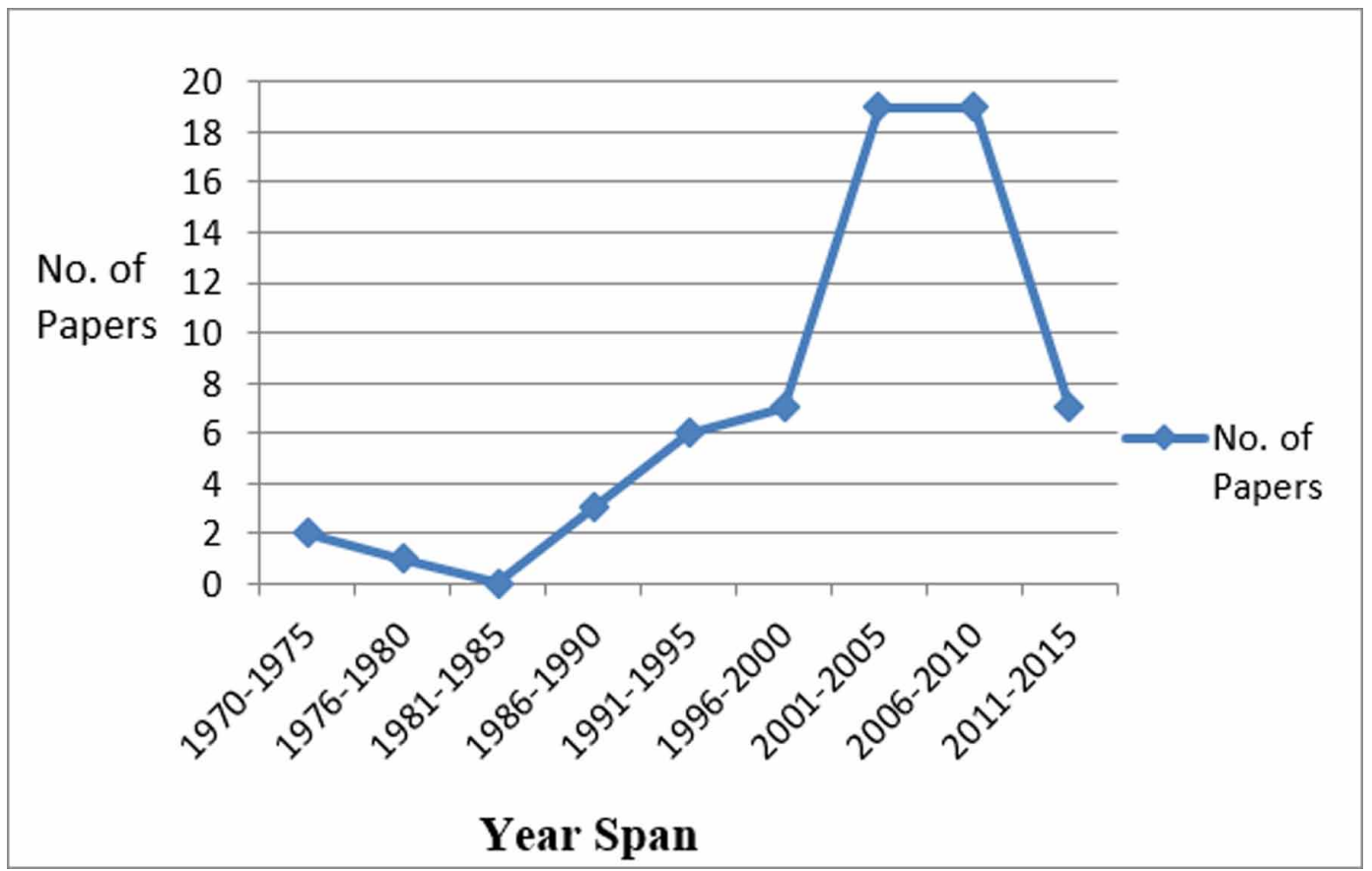

2007; Liew \& Kennedy, 2003; Pines et al., 2006; Sprivulis et al., 2006). It badly affects patient satisfaction (Spaite et al., 2002; Taylor \& Benger, 2004) and increases the number of patients who leave before being seen by the doctors also (Fernandes et al., 1997; Goldman et al., 2005). In many EDs major portion of the patient waiting time was due to the waiting times at various stages, particularly waiting time spent before being seen by a doctor, consultation time, patient waiting time for results of laboratory, average waiting time at the pharmacy and waiting in ED after admission are also contributors of patient's waiting time.

In the ED, every second is very important for patients. These times may be determinant of the interval between death and serious disability or life (Smeltzer \& Hand Curtis, 1987). Patient waiting time in the ED is one of the important factors in health care management and also determinate factors of patient satisfaction, as well as indicators for evaluating quality of health care services in ED (Eldabi $\&$ Paul, 2001). One finding showed main reasons of patient dissatisfaction was $67 \%$ of patient waiting time and $19 \%$ of absence of effective relationship in between patients and medical care staff (Choyce $\&$ Maitra, 1996). From recent years, patient waiting time in the emergency department in England was increased to 4 hours and in Canada up to 2 hours (Audit Commission, 2001). Some studies in health care sector in Iran showed that the average patient waiting time in the ED is much higher and this issue causes many problems in health care service processes at these EDs (Aeenparast, 2006). Long waiting time of healthcare services illustrates weak management, no coordination and inadequate of resources (Young \& Eldabi, 2006). Many studies from recent years in Canada show that the number of patients that visit the ED increased to 14 million per year and in Britain to beyond 15 million in a year (Canadian Institute for Health Information, 2005; Lane \& Monefeld, 2000).

Patient waiting time in ED is serious and rising problem destroying the 'safety net' of the health care system. Simulation tools provide an important method to investigate and analyze patient waiting time in ED and find the solutions to these problems. Through systematic review of ED simulation literature from 1970 to 2013 focusing on patient waiting time, authors have identified a variety 
of features that these studies have in common. Graph 1 represents the year (5 year span) and the corresponding number of studies.

\subsection{Role of Simulation Modeling}

Simulation, an important systems analysis tool, gives great flexibility in testing scenarios, hypotheses, and specifically re-engineering ideas in health care system. It can be applied as research tool, decision making tool and for the purpose of planning model (Matko et al., 1992). As per Pritsker, (1986) simulation can be defined as the development of a mathematical / logical model of a system and the experimental manipulation of the model on a computer.

From some years, researchers have successfully applied simulation methodology to construct models of complex systems and which was carried in real-time (Tavakoli et al., 2008). In these instances, the gain in system performance as a result of the application of simulation has been identified. As ED is a complex system, purely mathematical models such as linear or non-linear programming and other methods cannot be used for solving problems of ED. The preferable method is discrete event simulation. It can be used in solving health care resource allocation problems because it can deal with a dynamic health care system and with complicated interactions in between various components and processes (Weng \& Tsai, 2011)

\subsection{Objectives}

Few studies stated that their objectives were to reduce the patient waiting time in ED (Aboukanda \& Latif, 2013; Blake et al., 1996; Blasak \& Starks, 2003; Brailsford Sally, 2007; Bryant, 2011 a; Cabrera \& Luque, 2011; Elbeyli \& Krishnan, 2000; Evans, 1996; Gonzalez et al., 1997; Kırışa et al., 2010; Lane et al., 2000; McGuire, 1994; Mohamed et al., 2009; Pablo et al., 2008; Reid et al., 2005; Reyes et al., 2012; Shim \& Kumar, 2010; Tan et al., 2002) or to reduce the patient length of stay in ED (Gul \& Guneri, 2012; Khare et al., 2009; Mason, Hill, Mönch, \& Rose, 2008) or to improve quality of health care (Zeng et al., 2011). Some studies examined patient flows (Takakuwa \& Shiozaki, 2004) and bottlenecks in flows (Reid et al., 2005), causes of excessive wait times (Komashie \& Mousavi, 2005; Takakuwa \& Shiozaki, 2004), and patient throughput (Cabrera \& Luque, 2011; Samaha et al., 2003). A few studies also described the effects of introducing fast care plan for low acuity patients (Garcia \& Centeno, 1995), Long patient wait times for low acuity patients (Blake et al., 1996; Kırışa et al., 2010), High Length of patient stay in ED (Aboukanda \& Latif, 2013; Gul \& Guneri, 2012; Khare et al., 2009; Komashie \& Mousavi, 2005; Mason, Hill, Mönch, \& Rose, 2008; Mason, Hill, Mönch, Rose et al, 2008; Samaha et al., 2003), Lack of ED capacity (Gonzalez et al., 1997; Gorelick et al., 2005), High withdrawal rates of patients (Gonzalez et al., 1997), Number of ambulance diversion means ambulance carrying critical patient are diverted to another hospital from ED due to unavailability of bed or other facilities (Samaha et al., 2003) and Increased patient dissatisfaction (Cote, 2000). Several studies examined alternative staff schedules (Cbarnes et al., 1996; Clark \& Waring, 1987; Kırışa et al., 2010; Tan et al., 2002). Few studies assessed the effect of different staff schedules on wait times (Coats \& Michalis, 2001; Rossetti et al., 1999). As beds are very important resource in the ED, studies examined critical bed requirements (Lowery, 1992; Lowery, 1993) and the impact of bed availability on wait times of admitted patients (Elbeyli \& Krishnan, 2000; Lane et al., 2000), decision making aid (Kırışa et al., 2010), to investigate potential impacts on performance of ED by changing the aspects(resources) of ED (Melissa \& Erhan, 2008). These objectives of simulation studies are given in the Table 1 under the headings of Quality of Health care services.

\subsection{Modeling Techniques}

For the purpose of building emergency department model, there are a number of simulation methods. There are three simulation methods which are evaluated as discrete event simulation (DES), system dynamics (SD), and Agent-based simulation (ABS) for modeling a fictional hospital system. 
Table 1. Objectives of simulation studies

\begin{tabular}{|c|c|c|}
\hline $\begin{array}{c}\text { Serial } \\
\text { Number }\end{array}$ & Measures of Quality of Health care services & Reference number of papers \\
\hline 1 & Patient waiting time in ED & $\begin{array}{l}\text { (Aboukanda \& Latif, 2013; Aeenparast, } \\
\text { 2006; Audit Commission, 2001; Blake } \\
\text { et al., 1996; Blasak \& Starks, 2003; } \\
\text { Brailsford Sally, 2007; Bryant, 2011a; } \\
\text { Cabrera \& Luque, 2011; Choyce \& } \\
\text { Maitra, 1996; Elbeyli \& Krishnan, } \\
\text { 2000; Evans, 1996; Gonzalez et al., } \\
\text { 1997; Kirısa et al., 2010; Lane et al., } \\
\text { 2000; McGuire, 1994; Mohamed et } \\
\text { al., 2009; Pablo et al., 2008; Reid et } \\
\text { al., 2005; Reyes et al., 2012; Shim \& } \\
\text { Kumar, 2010; Tan et al., 2002; Young } \\
\text { \& Eldabi, 2006) }\end{array}$ \\
\hline 2 & Long patient wait times for low acuity patients & $\begin{array}{l}\text { (Blake et al., 1996; Kırışa et al., 2010; } \\
\text { Young \& Eldabi, 2006) }\end{array}$ \\
\hline 3 & Higher Length of patient stay in ED & $\begin{array}{l}\text { (Gul \& Guneri, 2012; Khare et al., } \\
\text { 2009; Komashie \& Mousavi, 2005; } \\
\text { Mason, Hill, Mönch, \& Rose, 2008; } \\
\text { Mason, Hill, Mönch, Rose et al, 2008; } \\
\text { Samaha et al., 2003) }\end{array}$ \\
\hline 4 & Lack of ED capacity & $\begin{array}{l}\text { (Gonzalez et al., 1997; Gorelick et al., } \\
\text { 2005) }\end{array}$ \\
\hline 5 & Quality of service & $\begin{array}{l}\text { (Aboukanda \& Latif, 2013; Zeng et } \\
\text { al., 2011) }\end{array}$ \\
\hline
\end{tabular}

Some studies applied various type of modeling technique including discrete-event (Blake et al., 1996; Coats \& Michalis, 2001; Komashie \& Mousavi, 2005; Takakuwa \& Shiozaki, 2004; Tan et al., 2002), systems dynamics (Lane et al., 2000), conceptual (Cabrera \& Luque, 2011) and mathematical modeling (Connelly \& Bair, 2004). A simulation model may be deterministic (if model does not contain any random variables) or stochastic (if model contain some or more random variables) (Kırışa et al., 2010). Stochastic processes are governed by probabilistic laws. They are applied to analyze different aspects of health care systems from 1950s (Cote, 2000). It is found that most often the ED was simulated as a stochastic system because the patient inter-arrival times and service times of patients are considered random variables.

The ED was many times, also modeled as a discrete system. Discrete event simulation has been used extensively in examining patient flows and allocation of resources in health care clinics and was the most popular simulation technique in the studies which were reviewed. Queuing models are considered as discrete-event models which are used to represent customers queuing to gain access to limited resources and have been used to simulate unscheduled patient arrivals in EDs, operating rooms, intensive care units, blood clinics, and X-ray departments. Some discrete-event models (Coats \& Michalis, 2001; Lowery, 1993) were written in SLAM (Simulation Language for Alternative Modeling). Pegden and Pritsker (2010) developed a process-oriented simulation language. Patients flow in ED can be pictorially represented by SLAM as a network consisting of different nodes and branches. Other discrete-event modeling tools include Arena (Aboukanda \& Latif, 2013; Blasak \& Starks, 2003; Connelly \& Bair, 2004; Kırışa et al., 2010; Komashie \& Mousavi, 2005; Lowery, 1993; Mason, Hill, Mönch, Rose et al, 2008; Samaha et al., 2003; Takakuwa \& Shiozaki, 2004), Extend (Connelly \& Bair, 2004; Cote, 2000; Kolker, 2008), SIMAN (Blake et al., 1996), and SIMUL-8 (Cabrera \& Luque, 2011; Coats \& Michalis, 2001), Process Model, Inc, Utah, version 5.2.0 (Kolker, 
Table 2. Types of data

\begin{tabular}{|l|l|l|}
\hline \multicolumn{1}{|c|}{ Serial Number } & \multicolumn{1}{|c|}{ Types of data } & \multicolumn{1}{c|}{ Reference number of papers } \\
\hline 1 & Patient inter-arrival times, & $\begin{array}{l}\text { (Shim \& Kumar, 2010; Tavakoli et al., } \\
\text { 2008; Weng \& Tsai, 2011) }\end{array}$ \\
\hline 2 & Health care service times & $\begin{array}{l}\text { (Aboukanda \& Latif, 2013; Blake et al., } \\
\text { 1996; Cabrera \& Luque, 2011; Gonzalez } \\
\text { et al., 1997; Kirışa et al., 2010; Lane et al., } \\
\text { 2000; McGuire, 1994; Tan et al., 2002) }\end{array}$ \\
\hline 3 & Length of patient stay & $\begin{array}{l}\text { (Aboukanda \& Latif, 2013; Gul \& Guneri, } \\
\text { 2012; Khare et al., 2009; Kolker, 2008; } \\
\text { Komashie \& Mousavi, 2005; Mason, Hill, } \\
\text { Mönch, \& Rose, 2008; Mason, Hill, Mönch, } \\
\text { Rose et al, 2008; Samaha et al., 2003) }\end{array}$ \\
\hline 4 & & (Tavakoli et al., 2008) \\
\hline
\end{tabular}

2008). Another modeling technique used was systems dynamics and Agent based modeling system (ABMS) (Cabrera \& Luque, 2011). The systems dynamics tool i-Think was used for such models (Lane et al., 2000). While discrete-event simulations can be used to create detailed models of sub systems within health care, systems dynamics enables a systemic view of the interactions of patient flows and information. Finally, conceptual modeling was used in some studies to create process maps and documentation.

\subsection{Data Sources and Collection Methods}

The simulation studies utilized various types of data source as inputs to their models. Types of data and respective data sources are given in Table 2 and 3 respectively. The data collection techniques included interviews with health care personnel and management, observations, historical data from ED databases, patient charts, time and motion studies. Hospital databases, patient charts, information systems, and medical records all play an important role in obtaining data on arrival patterns, time spent on different activities by care providers, and inter-arrival times and length of patient stay, patient inter-arrival times and health care service times (Elbeyli \& Krishnan, 2000; Kırışa et al., 2010; Samaha et al., 2003), volume and mix of patients (Elbeyli \& Krishnan, 2000), and duration of treatment (Lowery, 1993) were used to determine model inputs and outputs. RPF (Revised Process Form) MSO (Medical Staff Opinion) E (Electronically) (Gul \& Guneri, 2012), ERt (Electronic records) logs and patient records group discussions with some of the nursing staff (Cbarnes et al., 1996), reviewing the hospital record, questionnaire, Interviews (Aboukanda \& Latif, 2013).

\subsection{Study Findings}

Results obtained from different types of simulation modeling can be broadly categorized as resourcerelated, process-related and are given in the Table 4. Resources in the ED were health care personnel including nursing staff and doctors, equipment, and space resources. Resource-related focused on changing number of resources, allocation, and reallocation of resources. Process-related focused on changing or improving processes in the ED, including how processes were performed, as well as when certain processes were done.

\subsubsection{Resource-Related}

By applying optimum staff level (Gul \& Guneri, 2012), average patient length of stay was improved by $30 \%$ and also patient throughput was improved by $12.5 \%$. Similarly the simulation tool proved useful as a decision-making aid, allowing the user to identify the optimal deployment of human resources 
Table 3. Data collection sources

\begin{tabular}{|l|l|l|}
\hline \multicolumn{1}{|c|}{ Serial Number } & \multicolumn{1}{|c|}{ Data collection sources } & \multicolumn{1}{c|}{ Reference number of papers } \\
\hline 1 & Hospital databases & $\begin{array}{l}\text { (Elbeyli \& Krishnan, 2000; Kırışa et al., 2010; } \\
\text { Samaha et al., 2003) }\end{array}$ \\
\hline 2 & Information systems & $\begin{array}{l}\text { (Aboukanda \& Latif, 2013; Gul \& Guneri, } \\
\text { 2012; Komashie \& Mousavi, 2005; Mason, Hill, } \\
\text { Mönch, Rose et al, 2008; Samaha et al., 2003) }\end{array}$ \\
\hline 3 & Patient charts & (Kirı̧sa et al., 2010) \\
\hline 4 & Medical records & $\begin{array}{l}\text { (Gul \& Guneri, 2012; Komashie \& Mousavi, } \\
\text { 2005; Mason, Hill, Mönch, Rose et al, 2008; } \\
\text { Samaha et al., 2003) }\end{array}$ \\
\hline 5 & Time and motion studies & $\begin{array}{l}\text { (Brailsford Sally, 2007; Bryant, 2011a; Elbeyli } \\
\text { \& Krishnan, 2000; Kirişa et al., 2010; Mohamed } \\
\text { et al., 2009; Pablo et al., 2008; Reid et al., 2005; } \\
\text { Reyes et al., 2012; Samaha et al., 2003; Shim \& } \\
\text { Kumar, 2010) }\end{array}$ \\
\hline 6 & & (Gul \& Guneri 2012) \\
\hline 7 & RPF (Revised Process Form) & (Gul \& Guneri 2012) \\
\hline 8 & MSO (Medical Staff Opinion) & (Cbames et al., 1996) \\
\hline
\end{tabular}

Table 4. Categorization of study findings

\begin{tabular}{|l|l|l|}
\hline \multicolumn{1}{|c|}{ Serial Number } & \multicolumn{1}{|c|}{ Categorization of study findings } & \multicolumn{1}{c|}{ Reference number of papers } \\
\hline 1 & Resource-related & (Aboukanda \& Latif, 2013; Cbarnes et al., \\
& & 1996; Coats \& Michalis, 2001; Connelly \& \\
& & $\begin{array}{l}\text { Bair, 2004; Gul \& Guneri, 2012; Kırışa et al., } \\
\text { 2010; Mason, Hill, Mönch, Rose et al, 2008; } \\
\end{array}$ \\
& & Melissa \& Erhan, 2008; Taboada et al., 2012) \\
\hline 2 & Process-related & (Garcia \& Centeno, 1995; Gorelick et al., \\
& & 2005; Lane et al., 2000; Pallin \& Kittell, 1992; \\
& & Samaha et al., 2003; Sanchez et al., 2006) \\
\hline
\end{tabular}

for attending a specific number of patients (Taboada et al., 2012). Patient having higher priority due to severity were initially determined and then their waiting times were reduced (Kırışa et al., 2010). Investigation of highly desirable personnel schedules for the emergency department reduced average length-of-stay of patients in the emergency department (Cbarnes et al., 1996). Simulation helped in reduction in length of patient stay in ED, improvements in patient satisfaction, and cost savings (Aboukanda \& Latif, 2013). It helped to reduce imaging bottlenecks and average treatment times for high- acuity patients (Connelly \& Bair, 2004).

Simulation model is used to investigate potential impacts by changing the following aspects of ED (physical layouts; number of beds; number and rate of patient arrivals; acuity of illness or injury of patients; access to radiology and pathology services; hospital staffing arrangements; and access to inpatient beds)(Melissa \& Erhan, 2008). It helped in improvement in left without being seen (LWBS), length of stay, door to room, door to doctor, emergency severity index 4 length of patient stay in ED, emergency severity index 5 length of patient stay in ED (Mason, Hill, Mönch, Rose et al, 2008), reduction in patient waiting time (WT) and length of stay (Aboukanda \& Latif, 2013; Kolker, 2008). 
The results of discrete event simulation of emergency department activity suggested that 3 additional nurses were needed to ensure desired clinical outcomes and also acquisition of an additional computed tomography scanner is recommended (Brenner et al., 2010). Simulation studies gave stress on two major resources other than beds: human and equipment resources. One cause of in-efficiency in ED is that due to the irregular demand, the staffs are idle at times and overworked at other times (Melissa \& Erhan, 2008). Hence, several simulation studies were interested in examining the effects of alternative staff schedules on waiting times and LOS (Clark \& Waring, 1987; Coats \& Michalis, 2001; Evans, 1996; Pallin \& Kittell, 1992; Tan et al., 2002). Rossetti et al. (1999) identified a schedule by simulating 18 attending staff schedules that decreased average patient time in the ED by 14.5 minutes/patient. Based on that simulation, they found that this schedule also reduced physician utilization and percentage of long patient visits. Coats and Michalis (2001) simulated and compared different shift patterns and found that the doctor shift pattern that best matched the patient arrival pattern resulted the shortest patient wait times. Evans (1996) simulated and tested different schedules containing different numbers of nursing staff and technicians but the same number of doctors as the actual system and found only a 5 minute reduction in average length of patient stay in ED.

\subsubsection{Process-Related}

Many studies stated that establishing a fast-track path for low acuity patients was effective in decreasing wait times without negatively impacting quality of care (Sanchez et al., 2006). Samaha et al. (2003) simulated fast-track system by directing all routine patients and found a considerable reduction in length of patient stay in ED. Pallin and Kittell (1992) simulated fast-track system by eliminating return visits and found a 50\% reduction in number of staff and resources due to the fast-tracking. Garcia et al. (1995) found that taking one nurse and bed from the ED and using them in a fast-track would significantly decreased patient flow time for low severity patients. McGuire (1994) also found that increasing the hours of the fast-track proved to decrease 16- minutes in length of patient stay in ED. Samaha et al. (2003) found that patient bedside registration could not reduce length of patient stay in ED and would not be economical to implement but, a recent study proved that introducing bedside patient registration in the emergency process decreased length of patient stay in ED (Gorelick et al., 2005).

\section{LIMITATIONS OF SIMULATION STUDIES}

Though these simulation studies provided important approach in solving problems of ED, they had limitations that affected their usefulness in helping in solving these problems.

First, flows of patients were viewed in these studies in simplistic and in series manner. There are two characteristics of patient flows in health care: clinical and operational (Cote, 2000). In the ED, the clinical and operational aspects of flows are often entangled since the patient's health condition (case type and level of acuity) typically decides which treatment 'stations' they visit. This creates a large variety flow of patients in the ED. Takakuwa and Shiozaki (2004) found 70patterns of patient flows for 9 patient types in a single ED. In the process of modeling, these varieties of patient flows are hard and time consuming. Hence, for the simplicity, most flows were modeled as linear, that is, patients moved in a chronological manner from station to station. But, in reality patients might go through several care processes at the same time. These overlaps and interdependencies between many components of patient flows were not modeled in the simulation studies.

Second, many simulation studies did not include information flows when modeling patient flows. The health care process can be considered as a sequential step of processing of information starting from the initial data collection of patient's condition to developing a hypothesis and checking it by compilation of more data (Reid et al., 2005). These information flows are a crucial aspect of the modeling in an ED but have not been addressed by the simulation literature.

Third, the lack of standardization of workflow, patient care practices, patient categories and variety, and patient flows across ED makes it difficult to design a simulation model of an ED. 
Fourth, the objective of data achievement is to approximate the parameters of the system and to validate the model. The cost, time, accuracy, and complexity associated with collecting the data for simulation models has been a challenge (Valinsky et al., 1975). Though different patient arrival patterns and patient data can usually be obtained from information systems, patient service and waiting times can only be obtained by observation and time and motion studies. But, placing researchers in $\mathrm{ED}$ is often difficult due to the nature of patient flow and the environment and patient privacy issues.

\section{FUTURE SCOPE FOR SIMULATION RESEARCH}

From the simulation studies it is found that, there are three possible suggestions for future research directions. First, human behavior factor is not considered and analyzed in these simulation models. Simulation researchers can build human-computer interaction to correlate the behavior of patients and health care providers to model human interactions as part of the ED. Second, in many simulation studies, ED was studied and considered as an isolated unit. There is a need to focus and stress more on the role of the ED with related the larger hospital system and the interactions in between ED and other hospital's units like ICCU, wards etc. Third, many simulation studies focused mostly on improving efficiency, optimizing processes and resources, and cutting costs. Very few concentrated on direct impact on patient care or reducing patient wait times, LOS, and patient dissatisfaction with health care service. Therefore, it is necessary to include necessary requirements for patient care into the simulation models.

\section{CONCLUSION}

Patient waiting time is serious and growing problem destroying the 'safety net' of the health care system. Simulation tools provide important methods to investigate patient waiting, excess length of patient stay in ED and investigate solutions to these problems. Through a review of the last 44 years of simulation research focusing on these problems in ED, we have identified a variety of features which are in common. Though simulation has been useful in identifying critical resources and process improvements that can improve or overcome these problems, these studies still have severe limitations that must be addressed. Many interventions proposed by the simulation studies have been ED specific. Future simulation efforts must include a patient point of view, the role of information and communication technologies, to develop solutions to ED problems. Simulation is a powerful tool that researchers can deploy to face these problems of ED. 


\section{REFERENCES}

Aboukanda, E., \& Latif, M. (2013). Exploiting simulation to reduce patient waiting time using a streaming strategy in an emergency department. International Journal of Advanced Technology \& Engineering Research, $3(2), 79-86$.

Aeenparast, A. (2006). Simulation in Outpatient's Services System: Model Proposing for Reducing Waiting Time for Outpatients inTehran Educational and General Hospitals in 2005 [Thesis]. Tehran, Iran: Iran University of Medical Sciences, Faculty of Medical Informatics \& Management.

Audit Commission. (2001). Accident and Emergency, Review of National Findings: October 2001. Audit CommissionPublications.

Blake, J. T., Carter, M. W., \& Richardson, S. (1996). An analysis of emergency room wait time issues via computer simulation. INFOR, 34(4), 263-272. doi:10.1080/03155986.1996.11732308

Blasak, R. E., \& Starks, D. (2003). Healthcare process analysis: the use of simulation to evaluate hospital operations between the emergency department and a medical telemetry unit. Proceedings of the 35th Conference on Winter Simulation, 1887-1893.

Brailsford Sally, C. (2007). Tutorial: Advances and Challenges in Healthcare simulation Modeling. Proceedings of the 2007 Winter Simulation Conference. doi:10.1109/WSC.2007.4419754

Brenner, S., Zeng, Z., Liu, Y., Wang, J., Li, J., \& Howard, P. K. (2010). Modeling and analysis of the emergency department at university of Kentucky chandler hospital using simulations. J Emerg Nurs., 36, 303-310.

Bryant, D. (2011a). Simulation study to improve quality of care in the emergency department of a community hospital. Journal of Emergency Nursing, 1-7.

Cabrera, E., \& Luque, E. (2011). Optimization of Healthcare Emergency Departments by Agent-Based Simulation. Procedia Computer Science International Conference on Computational Science, 4, 1880-1889.

Canadian Institute for Health Information. (2005). Understanding emergency department wait time. Author.

Cbarnes, J. M., Morrice, D. J., Brunner, D. T., \& Slvain, J. (1996). A simulation model for evaluating personnel Schedules in a hospital emergency department. Proceedings of the 1996 Winter Simulation Conference.

Choyce, M. Q., \& Maitra, A. K. (1996, July 1). 996 Satisfaction withthe Accident and Emergency Department, a Postal Survey of General Practitioners' Views. Journal of Accident \& Emergency Medicine, 13(4), 280-282. doi:10.1136/emj.13.4.280 PMID:8832351

Clark, T. D., \& Waring, C. W. (1987). A simulation approach to analysis of emergency services and trauma center management. Proceedings of the 19th Conference on Winter Simulation, 925-934. doi:10.1145/318371.318717

Coats, T. J., \& Michalis, S. (2001). Mathematical modelling of patient flow through an accident and emergency department. The Emergency Medical Journal, 18(3), 190-192. doi:10.1136/emj.18.3.190 PMID:11354210

Connelly, L. G., \& Bair, A. E. (2004). Discrete Event Simulation of Emergency Department Activity: A Platform for System-level Operations Research. Academic Emergency Medicine, 11(11), 1177-1185. doi:10.1197/j. aem.2004.08.021 PMID:15528582

Cote, M. J. (2000). Understanding patient flow. Decision Line, 31, 8-10.

Diercks, D. B., Roe, M. T., \& Chen, A. Y. (2007). Prolonged emergency department stays of non-ST segmentelevation myocardial infarction patients are associated with worse adherence to the American College of Cardiology/American Heart Association guidelines for management and increased adverse events. Ann Emerg Med., 50(5), 489-496.

Elbeyli, S., \& Krishnan, P. (2000). In-patient flow analysis using ProModel simulation package. Proceedings of FREC SPOO-02.

Eldabi, T., \& Paul, R. J. (2001). A Proposed Approachfor Modeling Healthcare systems for understanding Arlington, Virginia, USA. Proceedings of the 33nd Conferenceon Winter Simulation, 9-12. 
Evans, G. W. (1996). A simulation model for evaluating personnel schedules in a hospital emergency department. Proceedings of the 28th Conference on Winter Simulation, 1205-1209. doi:10.1145/256562.256933

Fernandes, C. M., Price, A., \& Christenson, J. M. (1997). Does reduced length of stay decrease the number of emergency department patients who leave without seeing a physician? The Journal of Emergency Medicine, 15(3), 397-399. doi:10.1016/S0736-4679(97)00030-9 PMID:9258798

Garcia, M. L., \& Centeno, C. (1995). Reducing time in an emergency room via a fast-track. Proceedings of the $27^{\text {th }}$ Conference on Winter Simulation, 1048-1053. doi:10.1109/WSC.1995.478898

Goldman, R. D., Macpherson, A., Schuh, S., Mulligan, C., \& Pirie, J. (2005). Patients who leave the pediatric emergency department without being seen: A case-control study. Cmaj PubMed, 172(1), 39-43. doi:10.1503/ cmaj.1031817 PMID:15632403

Gonzalez, C. J., Gonzalez, M., \& Rios, N. (1997). Improving the quality of service in an emergency room using simulation animation and total quality management. Computers \& Industrial Engineering, 23(1/2), 87-100. doi:10.1016/S0360-8352(97)00049-1

Gorelick, M. Y., Yen, K., \& Yun, H. (2005). The effect of in-roomregistration on emergency department length of stay. Annals of Emergency Medicine, 45(2), 128-133. doi:10.1016/j.annemergmed.2004.08.041 PMID:15671967

Gul, M., \& Guneri, A. (2012). A computer simulation model to reduce patient length of stay and to improve resource utilization rate in an emergency department service system. International Journal of Industrial Engineering, 19(5), 221-231.

HSHRC. (n.d.). hshrc.gov.in/wp-content/uploads/Guidelines-for-Accident-and-Emergency-Department-_.pdf

Khare, R. K., Powell, E. S., Reinhardt, G., \& Lucenti, M. (2009). Adding More Beds to the Emergency Department or Reducing Admitted Patient Boarding Times: Which Has a More Significant Influence on Emergency Department Congestion? Annals of Emergency Medicine, 53(5), 575-585. doi:10.1016/j. annemergmed.2008.07.009 PMID:18783852

Kırışa, S., Yüzügüllüb, N., Ergünc, N., \& Çevik, A. (2010). A knowledge-based scheduling system for Emergency Departments. Knowledge-Based Systems, 23(8), 890-900. doi:10.1016/j.knosys.2010.06.005

Kolker, A. (2008, October). Effect of Patient Length of Stay on ED Diversion. Journal of Medical Systems, 32(5), 389-401. doi:10.1007/s10916-008-9144-x PMID:18814495

Komashie, A., \& Mousavi, A. (2005). Modeling emergency departments using discrete even simulation techniques. Proceedings of the 37th Conference on Winter Simulation, 2681- 2688.

Lane, D. C., \& Monefeld, C. (2000, May). Looking in the wrong place for healthcare improvements: A system dynamics study of an accident and emergency department. The Journal of the Operational Research Society, 51(5), 518-531. doi:10.1057/palgrave.jors.2600892

Lane, D. C., Monefeldt, C., \& Rosenhead, J. V. (2000). Looking in the wrong place for healthcare improvements: a system dynamics study of an accident and emergency department. Journal of the Operations Research Society, 51(9), 518-531.

Liew, D., \& Kennedy, M. P. (2003). Emergency department length of stay independently predicts excess inpatient length of stay. Medicine Journal., 179(10), 524-526. doi:10.5694/j.1326-5377.2003.tb05676.x PMID:14609414

Lowery, J. C. (1992). Simulation of a hospital's surgical suite and critical care area. Proceedings of the 24th Conference on Winter Simulation, 1071-1078. doi:10.1145/167293.167839

Lowery, J. C. (1993). Multi-hospital validation of critical care simulation model. Proceedings of the 25th Conference on Winter Simulation, 1207-1215. doi:10.1145/256563.257007

Mason, S. J., Hill, R. R., Mönch, L., \& Rose, O. (2008). Improving patient flow in a hospital emergency department. Proceedings of the 2008 Winter Simulation Conference, 1526-1531.

Mason, S. J., Hill, R. R., Mönch, L., Rose, O., Jefferson, T., \& Fowler, J. W. (2008). Improving patient flow in a hospital emergency department. Proceedings of the 2008 Winter Simulation Conference, 1526-1531.

Matko, , Karba, , \& Zupancic, . (1992). Simulation and Modelling of Continuous Systems. Prentice-Hall. 
McGuire, F. (1994). Using simulation to reduce length of stay in emergency departments. Proceedings of the 26th Conference on Winter Simulation, 861-867. doi:10.1109/WSC.1994.717446

Melissa, , DErhan, , K. (2008). Hospital Emergency Department Simulation for Resource Analysis. Industrial Engineering \& Management Systems, 7(2), 133-142.

Mohamed, A., Talal, M., \& Alkhamis. (2009). Simulation optimization for an emergency department healthcare unit in Kuwait. European Journal of Operational Research, 198, 936-942.

Pablo, S., Vincent, S., French, C. J., Puterman, M. L., \& Tyldesley, S. (2008). Reducing patient wait times and improving resource utilization at British Columbia Cancer Agency's ambulatory care unit through simulation. Health Care ManagSci, 9103-9111.

Pallin, A., \& Kittell, R. P. (1992). Mercy Hospital: Simulation techniques for ER processes. Industrial Engineering (American Institute of Industrial Engineers), 24(2), 35-37.

Pines, J. M., Hollander, J. E., Localio, A. R., \& Metlay, J. P. (2006). The association between emergency department crowding and hospital performance on antibiotic timing for pneumonia and percutaneous intervention for myocardial infarction. Academic Emergency Medicine, 13(8), 873-878. doi:10.1197/j.aem.2006.03.568 PMID:16766743

Pritsker, A. (1986). Introduction to Simulation and SLAM II. John Wiley \& Sons, Inc.

Reid, P. P., Compton, W. D., \& Grossman, J. H. (2005). Building a Better Delivery System: A New Engineering/ Health Care Partnership. National Academies Press.

Reyes, F., Cadarso, C., \& Martínez, A. (2012). Applying a simulation model in order to manage waiting lists for hospital inpatient activity in an EU region. Mathematical and Computer Modelling, 1-7.

Rodi, S. W., Grau, M. V., \& Orsini, C. M. (2006). Evaluation of a fast track unit: alignment of resources and demand results in improved satisfaction and decreased length of stay for emergency department patients. QualManag Health Care, 15(3), 163-170.

Rossetti, M. D., Trzcinski, G. F., \& Syverud, S. A. (1999). Emergency department simulation and determination of optimal attending physician staffing schedules. Proceedings of the 31st Conferenceon Winter Simulation, 1532-1540. doi:10.1145/324898.325315

Samaha, S., Armel, W. S., \& Starks, D. W. (2003). Emergency departments I: the use of simulation to reduce the length of stay in an emergency department. Proceedings of the 35th Conference onWinter Simulation.1907-1911.

Sanchez, M., Smally, A., Grant, R., \& Jacobs, L. M. (2006). Effects of a fast track area on emergency department performance. The Journal of Emergency Medicine, 31(1), 117-120. doi:10.1016/j.jemermed.2005.08.019 PMID: 16798173

Shim, S. J., \& Kumar, A. (2010). Simulation for emergency care process re-engineering in hospitals. Business Process Management Journal, 16(5), 795-805. doi:10.1108/14637151011076476

Smeltzer, C., \& Hand Curtis, L. (1987). An Analysis of Emergency Department Time: Layingthe Groundwork for Efficiency Standards. QRB. Quality Review Bulletin, 13(7), 240-242. doi:10.1016/S0097-5990(16)30140-3 PMID:3116483

Spaite, D. W., Bartholomeaux, F., Guisto, J., Lindberg, E., Hull, B., Eyherabide, A., Lanyon, S., Criss, E. A., Valenzuela, T. D., \& Conroy, C. (2002). Rapid process redesign in a university-based emergency department: Decreasing waiting time intervals and improving patient satisfaction. Annals of Emergency Medicine, 39(2), 168-177. doi:10.1067/mem.2002.121215 PMID:11823772

Sprivulis, P. C., Da Silva, J. A., Jacobs, I. G., Frazer, A. R., \& Jelinek, G. A. (2006). The association between hospital overcrowding and mortality among patients admitted via Western Australian emergency departments. The Medical Journal of Australia, 184(5), 208-212. doi:10.5694/j.1326-5377.2006.tb00203.x PMID:16515429

Taboada, M., Cabrera, E., Iglesias, M. L., Epelde, F., \& Luque, E. (2012). Agent-based emergency decisionmaking aid for hospital emergency departments. Emergencias, 24, 189-195.

Takakuwa, S., \& Shiozaki, H. (2004). Functional analysis for operating emergency department of a general hospital. Proceedings of the 36th Conference on Winter Simulation. 
Tan, B. A., Gubaras, A., \& Phojanamongkolkij, N. (2002). Schedule evaluation: simulation study of Dreyer Urgent Care Facility. Proceedings of the 34th Conference on Winter Simulation, 1922-1927.

Tavakoli, S., Mousavi, A., \& Komashie, A. (2008). Flexible Data Input Layer Architecture (FDILA) for Quick Response Decision Making Tools in Volatile Manufacturing Systems. Proceedings of the IEE, ICC'08 miniconference, 5515-5520 doi:10.1109/ICC.2008.1034

Taylor, C., \& Benger, J. R. (2004). Patient satisfaction in emergency medicine. Emergency Medicine Journal, 21(5), 528-532. doi:10.1136/emj.2002.003723 PMID:15333521

Valinsky, D., Spears, J., \& Young, J. P. (1975). Operations Research in Health Care: A Critical Analysis. John Hopkins University Press.

Weng, S., \& Tsai, B. (2011). Using simulation and data envelopment analysis in optimal Healthcare efficiency allocations. Proceedings of the 2011 Winter Simulation Conference.

Young, T., \& Eldabi, T. (2006). Simulating A and ESystems: More of the same or Lesson Learned. Proceedings of the2006 OR Society Simulation Work Shop.

Zeng, Z., Ma, X., Hu, Y., Li, J., Bryant, D., \& Columbus, K. Y. (2011). A simulation study to improve quality of Care in the emergency department of a Community hospital. Journal of Emergency Nursing, 1-7.

Shailesh Narayanrao Khekale, M-Tech, Ph.D., is working as Assistant Professor at Cummins College of Engineering for Women, Nagpur. He has seventeen-year experience including Industrial and teaching. He has published seven research papers in reputed journals and read papers in three national conferences.

Ramesh D. Askhedkar (PhD), Principal (Rtd.), K. D. K. College of Engineering, Nagpur, Ex. Professor, VRCE, Nagpur, supervised more than 15 research scholars for Ph.D, published 55 research papers in International and national journals, wrote 3 books and presented 61 papers in international and national conferences.

Rajesh H. Parikh (PhD), Professor, Mechanical Engineering, K. D. K. College of Engineering, Nagpur, Ex-Principal, Umrer College of Engineering, Umrer and Bhausaheb Mulak College of Engineering, Butibori, supervised 3 research scholars, published 15 research papers in International and national journals and presented 10 papers in international and national conferences and has thirty years teaching experience. 